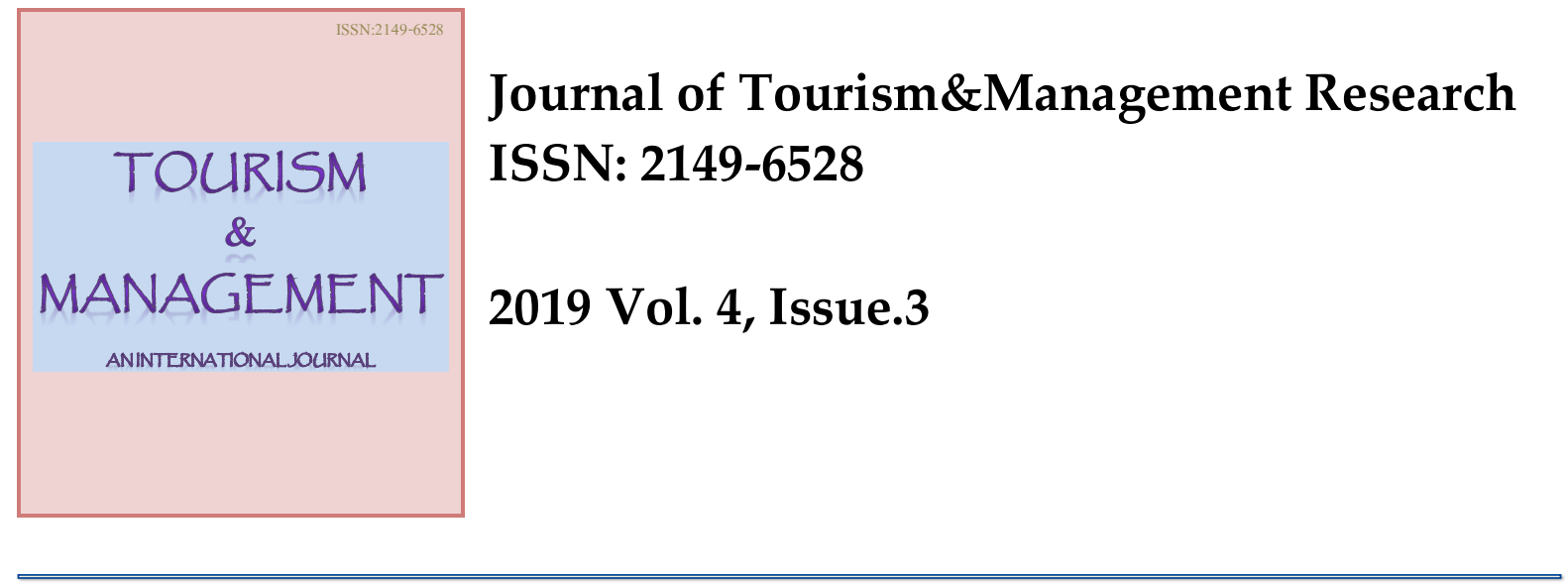

\title{
Cooperation Agreements and Customer Portfolio Management in Hotel Industry: The Airline Market Segment
}

\begin{abstract}
This paper aims to fill the gap in the literature regarding business-to-business (B2B) cooperation agreements between hotels and airlines, providing the readers with insights regarding the airline market segment in the hotels' customer portfolio management and their benefits for both parties. Literature review includes legislation issues, operations management and customer service management process, as a catalyst for these agreements. A hidden tourism business sector is also presented and refers to intermediaries that often handle such agreements. Hotels and airlines are tourism businesses and cooperating bodies aiming at high quality customer service and travel experience optimization. This dimension is not met in the relevant literature and therefore, this paper contributes to the theory with business insights of such B2B cooperation environment. Empirical methodology includes a primary survey with questionnaires distributed in the five-star hotel units of Athens, aiming to investigate their agreements with the airlines operating from Athens International Airport. The results highlight the background, the conditions and the benefits that both hotels and airlines gain from such business-to-business contracts and are used to evaluate airline market segment for the hotel industry, underlining its contribution in occupancy rates and revenues, as well as in seasonality mitigation, among others.
\end{abstract}

Keywords: hotels, airlines, cooperation agreements, customer portfolio management, travel industry

JEL Classification: Z31, M21, L93

Submitted:13/07/2019; Accepted:25/10/2019

Konstantinos Sergopoulos, Lecturer. University of West Attica, Department of Tourism Management. Aghiou Spyridonos 28, 12243, Egaleo, Greece. Tel. +306932019303

Email: sergopoulos@gmail.com

Ioulia Poulaki, Assistant Professor. (Corresponding Author). University of Patras, Department of Tourism Management. M. Alexandrou 1, 26334, Patras, Greece. Tel. +306970059478

Email: poulakiloulia@gmail.com 


\section{Introduction}

In the travel service industry, cooperative relationships among organizations are increasingly referred to as a crucial factor for organizational performance and survival (Ku et al., 2012). Strategic alliances are often defined as long-term cooperative agreements between two or more companies of similar or interrelated business sectors aiming on mutual economic benefits. These agreements involve the sharing of partners' resources to enhance their strategic objectives. Tourism companies are dealing with continuous changes in consumption patterns of demanding consumers and thus, they are trying to develop strategic partnerships in a travel related network to gain benefits such reduced competition, more efficient distribution, risk and resources sharing and new market opportunities. Therefore, travel industry players, namely hotels, airlines, travel agencies, car rentals, banking, national tourism organizations, maritime transport are forming partnerships to create advantages and mutual benefits (Doğan et al., 2012)

Hotels and airlines are two fundamental sectors of the tourism industry and highly connected each other since the travel requires transport and accommodation and in most of the cases, airplanes and hotel rooms are preferred by the tourists, so they are commonly included in travel packages distributed by the travel agents. However, hotels and airlines as main pillars of the travel industry, they are also coexisting in the framework of specified agreements from which both are benefited. There are several cases in the tourism literature where airlines and hotels are met to cooperate in a business-to-business (B2B) scheme. Some of these cases concern loyalty programs and award point redemption, where airlines and hotels team up to reward each other's loyalty members. American Airlines and Hilton Hotels partnership in 2014, Delta Airlines and Starwood (currently a brand name of Marriott International hotel chain) hotel chain partnership in 2013, United Airlines and Marriot partnership in 2013, are exceptional paradigms of beneficial partnerships of airline and hotels (Martin, 2014). Other types of cooperation refer to crew accommodation or airline disruption management, where hotels are highly involved to airline irregular operations (IROPs) efficiency, especially when it comes to distressed passengers' hotel accommodation upon airport overnights (International Air Transport Association, 2014)

Admittedly, there are companies to operate as airline partners and access large data bases of hotel inventories to accommodate airline crews or distressed passengers in the best available room prices targeting special offers. In fact, these companies cover spatially a sufficient number of countries to respond in airlines' wide range networks (Hotel Solutions Ltd, 2019; TravellianceInc, 2019). From the airline perspective, the issue of cost reduction in disruption management and crew accommodation in sufficiently covered through several research methodologies and outcomes based on prediction and deterministic or even stochastic model development that include all aspects of airline management and operations (Barnhart et al., 2003).

Nonetheless, in the relevant literature review, a gap is observed when it comes to hotel perspective and business aspect in such processes. Undoubtedly, hotels are also engaged with airlines in cooperative agreements from which they are also benefited. Familiarization (fam) trips and loyalty programs in the context of customer relations management bring together both tourism industry sectors.

The purpose of this paper is to fill this gap by highlighting the potential benefits gained for hotels through their cooperation with airlines in a B2B environment in addition to the airline ones. In this context, the aim of this paper is to investigate the cooperative service agreement schemes formed between airlines and hotels, when it comes to airline crew, airline staff on duty and distressed passenger hotel accommodation and the benefits generated for the hotel companies as illustrated through their key performance indicators (KPIs) such as increase in occupancy rates and revenues, additional revenues produced from food and 
beverage departments, mitigation of seasonality, etc. In the following sections the background of B2B environment between airlines and hotels is developed, the research question resulting from literature review gap, the research methodology and the primary survey details along with the findings and the conclusions. The way forward is suggested as well.

\section{Literature review}

\subsection{Hotel Accommodation in Airline Operations}

In this section the multidimensional need of hotel accommodation for the airline operations is developed. According to International Air Transport Association (2014), crew accommodation and disruption management are the most common and significant part of operations and irregular operations that airline operation control centers deal with, when the flight schedule runs in real time.

Crew accommodation - The complexity of the airline operations, when it comes to network structure, flight scheduling and crew resources, frequently demands the overnight of the crew members in the hubs used by the airlines to optimize the "puzzle" of the operations. Consequently, crew accommodation is an inevitable cost for the airlines to afford, so they try to minimize it through specific agreements signed by the carriers and selected hotels, per hub/destination, in order to assure room availability at any time point and at the lowest possible room rate.

Legislation and passenger rights $(261 / 2004 / E C)$ - The so-called "Passenger rights" regulation published in the official journal of European Union as of February 2004 (Council of the European Union, 2004) and concerns the establishment of common rules on compensation and assistance to passengers in the event of denied boarding and of cancellation or long delay of flights. The subject of this regulation is the specification of the minimum rights for passengers that experience boarding denial, flight cancellation or delayed flight. In the document are also specified the subject and several definitions for the parties involved. Passenger rights are defined per case of irregular operations (IROPs) and company's obligations are analyzed in detail per case (articles 1-2). Article 3 of the regulation describes its scope and where this shall be applied. Furthermore, articles 4-6 determine passenger rights when irregular operations are related with the main processes of denied boarding passenger, flight cancellation and flight delay. It is worth mentioning that there are cases when the airline denies boarding to a passenger for two main reasons: No show based overbooking techniques with the risk that all passengers may show up at the departure gate or, equipment downgrade due to operational reasons (aircraft with lower seat capacity). In both cases, respective number of passengers should stay behind voluntarily or involuntarily.

Apart from specific services that airline should provide in all of these cases, compensation is given to each passenger for the inconvenience that has been provoked due to airline's IROPs, while the amount of the compensation is strongly related with travel distance. Additionally, hotel accommodation should be provided where needed. More specifically, in the articles 7-9 there is a detailed reference in the main passenger rights which are (Council of the European Union, 2004):

- Right to compensation

- Right to reimbursement of re-routing

- $\quad$ Right to care

Additionally, several following articles are referred to the passengers with particular reservations and other useful details regarding the application of the regulation. As mentioned before, the compensation amount depends on the travel distance. In fact, there are three categories of compensation (short/medium/long haul flights). Highlighting the passenger "right to care", among other services provision, hotel accommodation is offered by the airlines in cases (Council of the European Union, 2004): 
- Where a stay of one or more nights becomes necessary, or

- Where a stay additional to that intended by the passenger becomes necessary.

Transport from the airport to the accommodation unit should be also ensured by the airline. Passenger rights regulation has been implemented to protect distressed passengers from any further inconvenience would be caused if airlines wouldn't have the willingness to compensate them. Long before the EU regulation 261/2004 there were indeed airlines that handled with care their distressed passengers, without this to be obligatory or a common practice.

\subsection{Distressed Passengers and Customer Service Management}

Airline disruption management has emerged with the rise of $21^{\text {st }}$ century driven by costcutting and efficiency in airline disruption methods. The three main aspects of airline management are (Kohl et al., 2007):

a) Passengers

b) aircraft

c) crew

Several reasons may cause disruption at the day of operations (departure date) and among others are:

a) Weather conditions

b) crew sickness

c) technical reasons/incidents

d) operational reasons (schedule changes, fleet type change)

Therefore, Kohl et al. (2007) defines Disruption Management as the process of monitoring and scheduling the resources close to the day of operations, otherwise Operations Control. Admittedly, disruption costs for airlines are very important and considering that flight delays impact for 2007 in the USA reached the $\$ 30$ billion, while almost a decade later, disruptions costs airlines and their customers the double amount of $\$ 60$ billion (Jimenez-Serrano and Kazda, 2017), one may say that the more efficient disruption management an airlines does, the less distressed passengers it has to handle and fewer costs to afford. The delay impact, among others, includes lost revenue, passenger rights (compensation and re-accommodation) and crew overtime costs (Lee et al., 2017). According to Gershkoff (2016) disruption costs consist the $8 \%$ of airline revenues. Apart from the operational costs of irregular operations, there is indeed an impact that any disruption causes in airline customers. According to Bolumole et al. (2004), customer service management process implementation is needed to proactively respond to situations before they negatively impact the customer. Both customer service management and disruption management are parts of service quality since the response to any schedule changes and customer care are included in an integrated service provision. According to Efthymiou et al. (2019), monitoring customer satisfaction, matters for airlines that aim to deliver quality services, in order to succeed in the competitive environment of nowadays, dealing with the evolution challenges. Schedule changes may occur for any possible reason (weather conditions, technical issues, crew sickness, etc). However, passengers consider them as a failure in service delivery process. Thus, airlines have to effectively manage disruptions and often customers' dissatisfaction and complaints, avoiding negative comments and preserve their loyalty. Quickly service recovery stands for customer issues resolution by empowering airline staff to deal with service recovery in tourism and hospitality industry (Efthymiou et al., 2019; Prideaux et al., 2006).

Furthermore, service recovery can be also defined as the actions taken by a company to appropriately respond in the failure which has led to passenger complaints and usually includes apologies, compensation and speed of recovery, among others (Efthymiou et al., 2019; Hart et al., 1990). Taking the aforementioned into consideration, it becomes explicit 
that hotel accommodation in airline operations should be inevitably secured and room availability is important at the moment that distressed passengers should be provided with it. Furthermore, ensuring hotel availability in advance may also reduce the costs of airline disruption management and crew accommodation. In this context, two main pillars of tourism industry, hotels and airlines, cooperate and, more specifically, the first have the role of suppliers, while the latter the role of consumers. Nonetheless, there are aspects of reverse transactions as well. Following section indicates all the dimensions of such B2B links between airlines and hotels.

\subsection{Market Segmentation in Hospitality Industry: The airlines}

Cooperation between hotels and airlines is multidimensional. Starting from marketing and ecommerce until operations management issues, there is always a link between hospitality and transportation businesses.

Loyalty programs and cooperation agreements - Loyalty programs are marketing tools to identity and reward loyal customers (Rayer (1996). Steinhoff and Palmatier (2014) define a loyalty program as "any institutionalized incentive system that attempts to enhance customers' consumption behavior over time". They can be met in many industries such as retail and hotel chains, airlines, and credit card companies among others (Hossain et al., 2017). Laskarin (2013) postulates that the evolution in information technologies contributed to the creation of a new generation of customer relations management (CRM) practices by marketing managers and one of them focuses on attending the guest and is the loyalty program. Customers can earn and redeem reward point in a wide network of partners that include all these business sectors. For airlines, frequent flyer programs (FFPs) are an effective loyalty customer expression. In fact, American Airlines introduced the first FFP in 1981, a practice that was followed by several industries including hotels, financial services and retailers that frequently cooperate in the context of such programs (Steinhoff and Palmatier, 2014). Aegean Airlines, United Airlines and Accor hotels are some examples that participate in loyalty program networks declaring, in their corporate websites, to be partners of hotels and airlines respectively. Additionally, loyalty concerns the identification and reduction of the factors that may lead to existing customer loss by handling effectively the complaints and recovering the service as previously described (Hossain et al., 2017).

Consequently, taking into account the aforementioned and disruption management processes as well, it is well understood that the connection between airlines and hotels is multi-dimensional. Apart from being both parts of a travel package, they are partners in loyalty programs, and they also cooperate in the context of airline quickly service recovery. Both dimensions concern service quality and customer service management, not to mention the operational significance of crew accommodation. Therefore, there are cooperation agreements between airlines and hotels to support such processes.

Hotel customer portfolio management and benefits from the airline market segment Summarizing two previous sections, in the context of loyalty programs, disruption management, distressed passenger handling and customer service management process, the airlines consist not only a partner but a regular client for hotel business, to be considered as a market segment contributing in customer portfolio expansion. In fact, customer portfolio management (CPM) is defined as "a practice by which a company analyses the role of different customers in providing current and future value in its customer base for developing a balanced customer structure through effective resource allocation to different customers or customer groups" (Terho and Halinen, 2007). Given the airlines are business as well, B2B cooperation agreements have been developed to support both tourism sectors, covering the needs of the airlines and generating benefits for the hotels, that include contribution in hotel occupancy (especially in low demand periods), in revenues, in seasonality mitigation etc. 
Undoubtedly, it is more complicated than seems it is and thus, there are cases that negotiations on these agreements are handled by intermediary businesses or third parties, to achieve the availability and rates in which both airlines and hotels would be satisfied.

\subsection{Intermediary Businesses and Third Parties}

There is a lack in literature review regarding the companies that handle tourism B2B agreements. Thus, a secondary internet research, regarding the cooperation between airlines and hotels, has led to the discovery of a business sector that operates as an intermediary between the both in order to arrange and manage the terms and conditions of such cooperative agreements, when it comes to the hotel inventories, the room rates and the airline operational needs, especially for the cases of crew accommodation and distressed passengers. These services can be handled by airline specialized teams or outsourced by such companies that closely cooperate with airline operations departments or provide them with relevant information technology (IT) solutions. Going deeper in their websites several business models are observed. There are companies which claim to be travel management partners to offer accommodation worldwide for airlines, when it comes to executive and workforce teams, crews and disrupted passengers (Hotel Solutions Ltd, 2019). Accommodation availability concerns a large database with access to hotel inventories to find and offer rooms that meet airline requirements at special discounted prices. Admittedly, it seems that United States and Canada markets are penetrated by such companies which are able to book on behalf of airlines even last minute rooms with 50\% discount off published offers and to propose solutions using digital technology that apply in all electronic devices so that airline staff can use from any location point, promising outstanding efficiency and valuable business intelligence, especially for irregular operations that need to react as fast as possible towards a flight schedule change (TravellianceInc, 2019). They also claim that customer feedback contributes to the evolution of these solutions. Furthermore, there are other companies that claim to deal with travel management services and hotel sourcing for organizations holding conferences, meetings or special events. Among others, they provide similar services for the airline industry like crew accommodation and transportation, as well as distressed passenger hotel accommodation that may be outsourced to such companies that claim to work closely with the airline staff to provide them with optimal solutions including cost efficiency and crew legislative requirements and guidelines for all types of airlines (domestic, international, commercial, charter carriers and private aviation) as trusted and respected partner for both airline and hotel industries, since it follows the regulatory framework for the airline crew and carry out onsite visits in the involved hotels in order to ensure that the standards required are met (Hotel Solutions Ltd, 2019). Consequently, as described in the above paragraphs, it seems that these companies concern a contemporary tourism business, an evolved and specialized tourism business-to-business (B2B) travel agency to offer a sophisticated handling of the agreements between airlines and hotels in favor of both targeting cost-cutting and operational efficiency for the first, while ensuring occupancy rate and revenue increase for the latter. However, it is difficult to estimate the size of this "hidden" tourism business sector since the offered services can also be offered by traditional travel agencies or can also be even combined with other products or services as well.

\section{Methodology}

\subsection{Developing the research question}

Based on the literature review regarding disruption management, loyalty programs and business insights from intermediaries, airlines need to easily access hotel room availability, so for operational reasons (crew accommodation, irregular operations and disruption management) as for commercial reasons as well (loyalty programs, customer service 
management process, quality service recovery). Therefore, they come into cooperation agreements with hotels in order to ensure a standard number of available rooms periodically in the minimum possible room rate, even in the peak season. Thus, they decrease their costs, apart from ensuring hotel room availability. On the other hand, hotel room occupancy by airlines during the winter low season, contributes in hotel key performance indicators (KPIs: occupancy rate, average rate, seasonality index and revenues). In the context of customer portfolio management and customer segmentation, airlines may be considered as a specific market segment for accommodation suppliers, since they are a group of customers who repeatedly purchase the goods or services of a business (here: hotels) and thus, a consistent source of revenue (Kotler, 2017). Businesses tend to grow their customer base. Therefore, hotels sign contracts with airlines in a context of cooperation agreement in order to retain this market segment in their customer portfolio.

Undoubtedly, such B2B cooperation agreements hide more benefits for both sides as well, whether in or out of the signed contract. An exceptional paradigm may be the fam trips that hotel staff enjoy, provided by the airlines in order to promote their services in the wider tourism and hospitality industry stakeholders.Taking all the above into consideration, it is worth investigating empirically these B2B cooperation agreements between airlines and hotels in order to verify if airlines are indeed considered as a market segment in hotels' customer portfolio, and how the latter manage it. Additionally, the contribution of airlines as a customer to the hotels is worth to be approached numerically in order to evaluate if such contribution worth the commitment in this type of cooperation agreements from the accommodation suppliers' side. Last but not least, the role and the dynamics of the participation of intermediaries or third parties in this process consists an extra input for tourism business activity, as they are not a widely known sector.Consequently, this paper aims to contribute to the theory of hotel customer portfolio management (CPM) by approaching and collecting related literature review and supporting it empirically with an investigation and analysis of the B2B cooperation agreements between airlines and hotels, illustrating all the aspects of such agreements in order to provide with industry insights tourism and hospitality readers.

\subsection{Research Design and Sampling}

Athens city has been chosen to be investigated with Athens International Airport to be the hub of airline operations and five-star ranking hotels as the accommodation suppliers of this research. Research methodology includes a primary survey with questionnaires distributed in five-star ranking hotel companies located in Athens in order to identify potential cooperative service agreements with airlines that operate from Athens International Airport (AIA). These questionnaires include questions regarding the existing contracts if any, the involved parties, the terms, the future plans, the numerical contribution of airline market segment to the hotels' KPIs and any suggestions for improvements. Data were collected and statistically analyzed with the use of statistical package for social sciences also taking into consideration the distance between AIA and each hotel.

More specifically, the primary survey includes a questionnaire which has been selected as the research method of mixed type of questions (closed and open) regarding the research question. Since it was distributed to the upper management executives of reservations and sales departments, the questionnaire was short and limited to core-questions, in order to extract the necessary data/information, without being time-consuming for the participants. In this way, authors avoided a possible denial of participation or missing values. The survey was conducted during winter season of 2019, and more specifically from mid-January to midFebruary in the five-star ranking hotels of the city of Athens except for the two airport hotels that are located in the wider region of Athens International Airport. Airlines tend to cooperate 
with high ranking hotels, so for their crew as for their distressed passenger accommodation and for this reason such units were selected for the primary research. According to the Hellenic Chamber of Hotels (2019), five-star units in Attica Region are 33, while research sample achieved 19 fully answered questionnaires, that is to say $58 \%$ of the total population. Thus, authors ensured the validation of the survey results, which have been processed with Statistical Package for Social Sciences (SPSS) to describe the sample responses.

\section{Results}

\subsection{Descriptive Statistics}

As mentioned above, the sample of the survey was 19 five-star hotels. The $74 \%$ of the participant units (14 hotels), have signed a cooperation agreement with at least one airline. Among the remaining 5 units, the one claimed that this is current and there are indeed future plans for such cooperation. The rest justified the nonexistence of an agreement due to low commercial interest or due to high occupancy rates. Hotel executives were asked for the time interval that such agreements are valid, which are presented in the table 1 below.

Table 1: Time interval of valid hotel-airline contracts.

\begin{tabular}{|l|c|c|c|c|}
\hline Time interval & Frequency & Percent & Valid Percent & $\begin{array}{c}\text { Cumulative } \\
\text { Percent }\end{array}$ \\
\hline less than 1 year & 5 & 26,3 & 35,7 & 35,7 \\
2-4 years & 4 & 21,1 & 28,6 & 64,3 \\
5-8 years & 3 & 15,8 & 21,4 & 85,7 \\
9-14 years & 1 & 5,3 & 7,1 & 92,9 \\
more than 15 years & 1 & 5,3 & 7,1 & 100,0 \\
N & 14 & 73,7 & 100,0 & \\
\hline
\end{tabular}

Another significant element elicited from the survey was the type of contract signed in the context of the cooperation agreement between the hotels and the airlines. $79 \%$ of the participants $(\mathrm{N}=14)$ declared that the contracts include binding fixed-term agreement with specific rentals accepted from both parties, $14 \%$ admitted collaboration with suggested rentals upon availability, while $7 \%$ work with both types of contracts. The majority of the hotel units collaborate directly with the airlines and only three of them use intermediaries/ third parties which were travel agents or specialized handlers to deal with the fulfillment of the contract requirements.Next section of questions concerned the 'experience based-benefits' that hotels are gaining by their cooperation with the airlines and are related with the occupancy rate and seasonality mitigation. The $79 \%$ of the hotel executives claimed that the units experience occupancy rate in an average of $8 \%$ (range 5-10\%) from the airline market segment, while the $57 \%$ seasonality mitigation, especially during low demand periods or winter season. Moreover, revenue is a particularly significant key performance indicator (KPI) to evaluate a market segment and airline contribution is presented in the following table 2.

Table 2: Airline market segment contribution to the total annual revenue (\%).

\begin{tabular}{|l|l|l|l|l|}
\hline $\begin{array}{l}\text { Airline market segment contribution to the } \\
\text { total annual revenue }(\%)\end{array}$ & Frequency & Percent & $\begin{array}{c}\text { Valid } \\
\text { Percent }\end{array}$ & $\begin{array}{c}\text { Cumulative } \\
\text { Percent }\end{array}$ \\
\hline
\end{tabular}




\begin{tabular}{|l|c|c|c|c|}
$0-5$ & 10 & 52,6 & 71,4 & 71,4 \\
$6-10$ & 3 & 15,8 & 21,4 & 92,9 \\
$11-20$ & 1 & 5,3 & 7,1 & 100,0 \\
$\mathrm{~N}$ & 14 & 73,7 & 100,0 & \\
\hline
\end{tabular}

For the majority of hotel units that cooperate with airlines $(\mathrm{N}=14)$ revenue generated from this market segment reaches $5 \%$ of the total annual revenue, while $21 \%$ of them declared to experience a contribution in revenue of $6-10 \%$. Additionally, $80 \%$ of the participants $(\mathrm{N}=14)$ admitted that airline market segment also contributes to the revenue of other departments, such as Food and Beverage (F\&B). A group of questions followed focusing on further details of hotel commercial strategy towards airline market segment and more specifically, on discounts in rentals assigned on airline staff and passengers. Indeed, there are discounted rates for airline employees (excluding crews), whether they are on duty or not in the $63 \%$ of the participant hotel units $(\mathrm{N}=19)$. This percentage increases to $68 \%$ when it comes to exclusively airline flight crews. At this point it is worth mentioning that regarding the frequency of accommodation of this group of customers, following table 3 illustrates the contribution in occupancy of hotel units that offer discounts $(\mathrm{N}=13)$. As presented in the valid percent value, $37,5 \%$ of the hotel units accommodate airline crews for more than 61 nights per year, a relevant high number for such specific market segment.

Table 3: Accommodation frequency of airline crews in hotel units offering discounted rates.

\begin{tabular}{|l|c|c|c|c|}
\hline Accommodation Frequency & Frequency & Percent & $\begin{array}{c}\text { Valid } \\
\text { Percent }\end{array}$ & $\begin{array}{c}\text { Cumulative } \\
\text { Percent }\end{array}$ \\
\hline low (<30 nights spent per year) & 2 & 15,3 & 25,0 & 25,0 \\
medium (31-60 nights spent per year) & 3 & 23,1 & 37,5 & 62,5 \\
high ( $>61$ nights spent per year) & 3 & 23,1 & 37,5 & 100,0 \\
Total & 8 & 61,5 & 100,0 & \\
$\mathrm{~N}$ & 13 & 100,0 & & \\
\hline
\end{tabular}

Furthermore, there are discounts and offers in rates for the occasion of airline distressed passengers. Among the participant hotel units $(\mathrm{N}=19), 74 \%$ declared discounted rates for this segment, an equal percentage to the hotels that have contracts with airlines and obviously they are referred to the terms signed by both parties. Last but not least, the spatial distribution of the hotel units is valuable to discuss, since apart from the hotel airports, the vast majority of the five-star ranking hotels are located around thirty kilometers from Athens International Airport and mainly in Athens city center, a table 4 indicates. Additionally, it worth to be 
mentioned that the two hotel units in the distance of 16-30 $\mathrm{km}$ from the airport are located in the south suburbs of the city by the coast of Athens Riviera.

Table 4: Hotel units distance from Athens International Airport.

\begin{tabular}{|l|c|c|c|c|}
\hline Distance from the airport & Frequency & Percent & $\begin{array}{c}\text { Valid } \\
\text { Percent }\end{array}$ & $\begin{array}{c}\text { Cumulative } \\
\text { Percent }\end{array}$ \\
\hline $0-5 \mathrm{~km}$ & 1 & 5,0 & 5,3 & 5,3 \\
$6-15 \mathrm{~km}$ & 1 & 5,0 & 5,3 & 10,5 \\
$16-30 \mathrm{~km}$ & 2 & 10,0 & 10,5 & 21,1 \\
$31-40 \mathrm{~km}$ & 15 & 75,0 & 78,9 & 100,0 \\
$\mathrm{~N}$ & 19 & 95,0 & 100,0 & \\
\hline
\end{tabular}

Finally, seasonality performance is quite significant for all tourism businesses, especially for the city hotels that operate all year round. Participants in the survey declared the airline market segment contribution concerns low demand periods, winter season, in some cases from October to April or in others from November to February, blunting seasonality phenomenon for the involved hotel units. At this point it is worth mentioning that, due to small number of survey population and the common pattern followed by the participant hotel units towards airline market segment and the B2B agreements, there was no statistics significance presents at any of statistical case tests that mainly concerned correlation Chi square test and Regression Linear simulation. Regarding the latter, coefficients presented statistically insignificant, while $\mathrm{R}$ square test appeared $2,1 \%$ with the respective adjusted one to reach $3,6 \%$, which cannot lead in an accurate population behavioral trend.

\subsection{Qualitative Data and Analysis}

As mentioned in the section of research methodology, several open type questions were included in the questionnaire in order to extract qualitative data for two main reasons. Firstly, open type questions to receive numerical answer were preferred in order to ensure the accuracy of the absolute numbers instead of a numerical range that might have been used for a respective closed type question. Secondly, the exact opinion of the participant for issues regarding the reason(s) for cooperation agreement nonexistence or what could be improved in the context of the cooperation agreements between hotels and airlines in order to further enhance them, would be very significant for the conclusions. The majority of the qualitative data have been incorporated in the descriptive statistics section, while for the last open question, most of the participants claimed that airlines need to accept higher rates especially during high demand periods. More specifically, they argued that such cooperation agreements are impeded from flourishing by airlines' intolerance in higher rates. High demand seasons are crucial time periods for the hotels to maximize or even maintain their revenues and other key performance indicators (occupancy, average rate). Thus, they restrict their availability for the needs of the airline market segment because the latter does not accept an increase in the rates during peak season. Nonetheless, there were others to express their doubts regarding the commercial interest of further developing airline market segment through this type of agreements. Furthermore, there were hotels to admit the win-win situation and ensure these agreements, while others have observed that distance factor affect negatively the cooperation from the airline side. 


\section{Conclusion, Implications and Limitations}

Research showed that there are indeed cooperation agreements to benefit both airlines and hotels. Airlines are benefited in the context of marketing and customer service management process, with loyalty programs, crew accommodation and quality service recovery upon irregular operations, while hotels are benefited by experiencing a contribution of $8 \%$ in average occupancy, which is significant for the low demand season, a contribution of $5 \%$ in their revenues, additional revenues for non-accommodation hotel departments, seasonality mitigation and again loyalty programs. Additionally, airlines may ensure staff discounts, while hotels may send sales staff to familiarization trips of new country markets travelling with discounted on their airline partners' network. In any case, such cooperation agreements could be further enhanced to benefit more both airlines and hotels, if better negotiations could be achieved, in terms of higher rate acceptance from the airlines side, in a potential exchange of better conditions in point redemption from the hotels side. Since the links between the two tourism business sectors are many, there should be terms and conditions that may optimize such cooperation agreements. Airlines are indeed an important market segment for the hotels and their customer portfolio management orientation. Below figure 1 summarizes the work of this paper highlighting the benefits for both sectors.

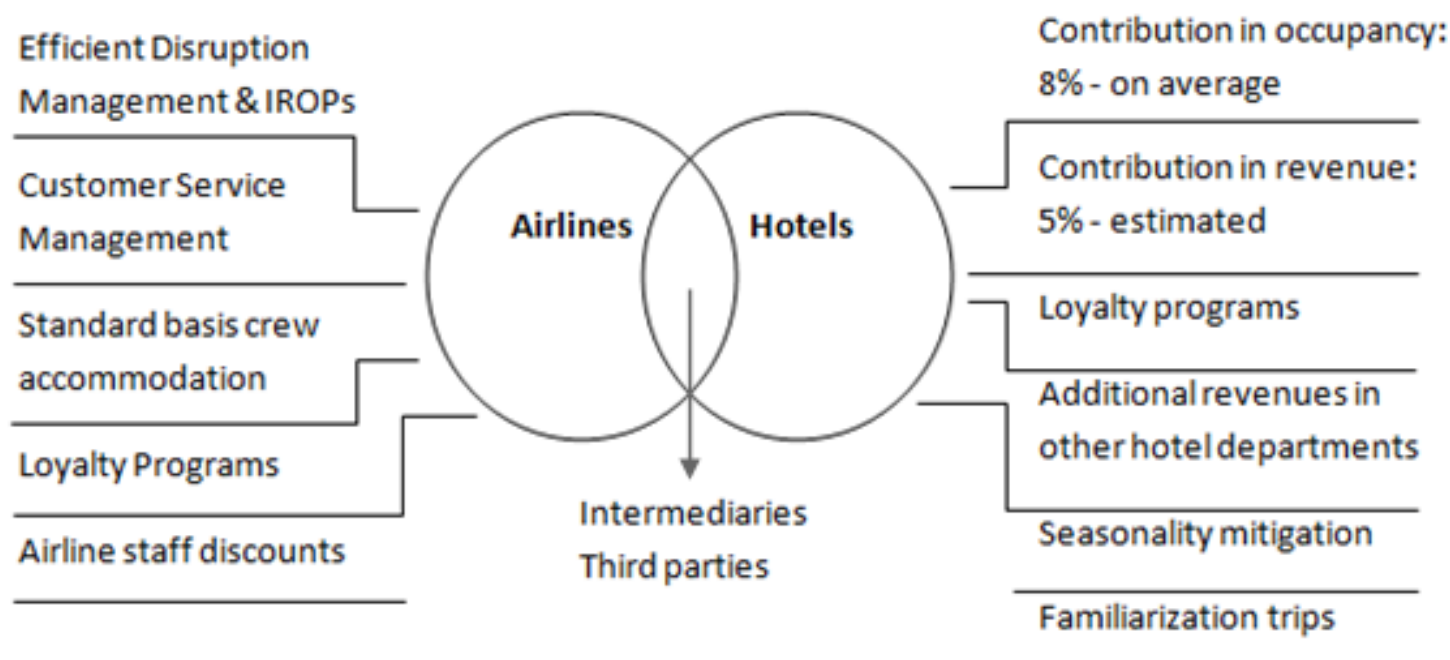

Figure 1: Cooperation agreements between hotels and airlines: structure and benefits.

More specifically, the figure presents the structure of the cooperation agreements between airlines and hotels and the benefits that both parties gain. Contracts can be signed directly with rate negotiations, terms and conditions set by the involved corporate teams. Otherwise, intermediaries/third parties may also handle the contract details, as companies that offer services to the airlines having already assured beneficial conditions upon negotiations with hotels. Airlines are benefited operationally since standard basis accommodation for crew is ensured, efficient disruption management is achieved by offering immediate accommodation to distressed passengers and crew. Commercially, airlines are benefited by the efficient Customer Service Management that reflects to the quality service recovery and by the partnerships in loyalty programs that are enhanced through such agreements. On the other hand, Hotels experience significant benefits in their key performance indicators, given that the survey indicated an average of 5\% in hotel annual revenues by the airlines market segment and $8 \%$ in hotel annual occupancy rate. Seasonality mitigation has also been declared as a result of these agreements, while additional revenues in other hotel departments are produced as well. Partnerships in loyalty programs are beneficial also for the hotels as an ancillary that 
tend to penetrate in tourism sector. Last but not least, airline staff discounts and familiarization trips are indirect benefits for both cooperating bodies and their staff.

Undoubtedly, there were research limitations that concerned the business nature of the study. Initially, actual data regarding occupancy rates, average room rates and contract financial details cannot be provided from the hotels nor from the airlines, so the real impact is impossible to be recorded. Moreover, Participants are, as mentioned in subsection 3.2, upper management executives of reservations and sales departments, that would deny participating if the questionnaire was big and time-consuming, due to their daily workload and responsibilities. Thus, there would be more data to collect if we could ensure their willingness to spend more time in the survey. Nonetheless, a future short survey with additional questions could be an option. Additionally, airline perspective would also be very helpful to conduct integrated conclusions on the topic. Further research also suggests the repetition of the same research in another geographical region, while even more detailed questionnaires could also be useful to further expand the findings with additional aspects and dimensions.

\section{References}

Barnhart, C., Belobaba, P. and Odoni, A.R. (2003).Application of Operations Research in the Air Transport Industry.Transportation Science, Vol. 37(4), pp.1526-5447.

Bolumole, Y., Lambert, D., Knemeyer, A.M. (2003). The Customer Service Management Process. The International Journal of Logistics Management. Vol. 14(2), pp. 15-31. Available at: https://doi.org/10.1108/09574090310806576. [Accessed 01 June 2019].

Council of the European Union (2004). Regulation (EC) No 261/2004 of the European Parliament and of the Council. Official Journal of the European Union. Available at: https://publications.europa.eu/en/publication-detail/-/publication/439cd3a7-fd3c-4da78bf4-b0f60600c1d6/language-en. [Accessed 12 March 2019].

Doğan, H., Barutçu, S., Nebioğlu O. and Doğan, I. (2012). Perceptions of Hotel Top Managers for Opportunities and Strategic Collaboration with a Foreign Partner in Tourism Sector: An Applied Research in Alanya Destination. Procedia - Social and Behavioral Sciences, 58, pp.1218-1227.

Efthymiou, M., Njoya, E.T., Lo, P.L., Papatheodorou, A. and Randall, D. (2019). The Impact of Delays on Customers' Satisfaction: an Empirical Analysis of the British Airways OnTime Performance at HeathrowAirport. Journal of Aerospace Technology and Management, Vol. 11, pp. 1-13.

Gershkoff, I. (2016). Amadeus Whitepaper: Airline Disruption Management. Travel Technology Research Ltd. Available online at: https://amadeus.com/documents/en/blog/pdf/2016/09/airline-disruption-managementwhitepaper-2016.pdf. [Accessed 30 April 2019].

Hart, C., Heskett, J. and Sasser, W. (1990). The Profitable art of service recovery. Harvard Business Review, Vol. 68(4), pp.148-156.

Hellenic Chamber of Hotels (2019). Statistics: Hotel Capacity in Greece 2018 - Per Region, Prefecture, Island. Available at: http://www.grhotels.gr/. [Accessed 01 May 2019].

Hossain, M.Z., Kibria, H. and Farhana, S. (2017). Do Customer Loyalty Programs Really Work in Airline Business? - A Study on Air Berlin. Journal of Service Science and Management, Vol. 10(4), pp. 360-375.

Hotel Solutions Ltd. (2019). About Us: Specialists in hotel sourcing, bidding and contracting. Available online at: http://www.hotelsolutionsltd.com/. [Accessed 01 Jun 2019].

Hotel Solutions Ltd. (2019). Our services: Professional sourcing for meetings and travel services. Available online at:http://www.hotelsolutionsltd.com/.[Accessed 01 Jun 2019]. 
International Air Transport Association (2014). Operations Control (OCC), Airline Cost Conference, Geneva 25-27 August 2014., Available online at: https://www.iata.org/whatwedo/workgroups/documents/acc-2014-gva/occ-3-occ.pdf.

Jimenez-Serrano, F.J., Kazda, A. (2017). Airline Disruption Management: Yesterday, today and tomorrow. Trasportation Research Proceedia, Vol. 28, pp. 3-10. Available at: https://doi.org/10.1016/j.trpro.2017.12.162. [Accessed 30 Apr 2019].

Kohl, N., Larsen, A., Larsen, J., Ross, A. and Tiourine, S. (2007). Airline Disruption Management - Perspectives, Experiences and Outlook. Journal of Air Transport Management, Vol. 13(3), pp.149-162.

Kotler, Ph. (2017). Marketing Management (15 ${ }^{\text {th }}$ edition). Just the Facts101-Textbook Key Facts. Content Technologies Inc (CTI) Reviews.eISBN 9781497095878.

Ku, E.C.S., Yang, C.M. and Huang, M.Y. (2012). Partner Choice: Adaptation of Strategic Collaboration Between Travel Agencies. Journal of Hospitality and Tourism Research, Vol. 37(4). pp.516-536.

Laskarin, M. (2013). Development of Loyalty Programs in the Hotel Industry. Tourism and Hospitality Management, Vol. 19(1), pp.109-123.

Lee, J., Marla, L. and Jacquilat, A. (2017). Dynamic Airline Disruption Management Under Airport Operating Uncertainty. Available at SSRN: http://dx.doi.org/10.2139/ssrn.3082518. [Accessed 30 Apr 2019].

Martin, G. (2014). Airlines and hotels team up to reward each other's loyalty program members, Forbes. Available online at: https://www.forbes.com/.

Prideaux, B., Moscardo, G. and Laws, E. (2006). Managing Tourism and Hospitality Services. Theory and International Applications.Oxforshire: CABI Publishing.

Steinhoff, L., Palmatier, R.W. (2016). Understanding loyalty program effectiveness: managing target and bystander effects. Journal of the Academy of Marketing Science. Vol. 44(1), pp. 88-107.

Terho, H. and Halinen, A. (2007). Customer portfolio analysis practices in different exchange contexts. Journal of Business Research, Vol. 60(7), pp.720-730.

Travelliance Inc. (2019). Services: Airlines. Available online at: https://travellianceinc.com/. [Accessed 01 Jun 2019].

Travelliance Inc. (2019). Hotel Partners. Available online at: https://travellianceinc.com/. [Accessed 01 Jun 2019].

\section{Author Biography}

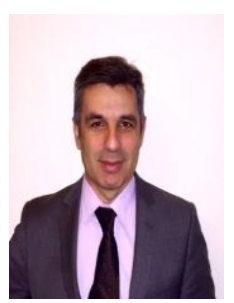

Konstantinos Sergopoulos has twenty two years of working experience in Marriott International Hotel Chain as the Head of the Front Office Department and Telesales Manager at Athens Ledra Marriott Hotel. He is also a Hotel Management Consultant. He has been teaching since 2003 Hotel Management and Hospitality at the University of West Attica, the Toulouse University, the Queen Margaret University, the Piraeus University, the Hellenic Open University. Furthermore, he is also an instructor of seminars aimed at hotel staff training across several departments (front office, sales \& marketing, housekeeping). His research interests are focused on Hotel Management and Hospitality fields. 
Dr loulia Poulaki is an Assistant Professor in the Department of Tourism Management at the University of Patras. She also collaborates as an Academic Teaching Staff in the Department of Tourism Management at the University of West Attica and in the postgraduate course in Tourism Business Administration at the Hellenic Open University. She has also been working in the Air Transport industry for ten years with experience in commercial and operational departments. Her research interests are focused on the fields of air transport and tourism, while her papers have been published in journals, book chapters and international conference proceedings. 